\title{
Propofol- $\mathrm{N}_{2} \mathrm{O}$ 를 사용한 제왕절개술 마취에서 마취유도제로서 Thiopental Sodium과 Propofol의 비교
}

\author{
한일병원 마취과, *서울대학교 의과대학 마취과학교실 \\ 황 정 원·오 용 석*·이 혜 정
}

$=$ Abstract $=$

\author{
Comparison of Thiopental Sodium and Propofol as an Induction Agent \\ in Propofol- $\mathrm{N}_{2} \mathrm{O}$ Anesthesia for Cesarean Sections
}

Jung Won Hwang, M.D., Yong Seok Oh, M.D.*, and Hye Jeong Lee, M.D.

Department of Anesthesiology, Hanil General Hospital, and ${ }^{*}$ College of Medicine, Seoul National University, Seoul, Korea

Background: We compared thiopental sodium with propofol as induction agents under propofol- $\mathrm{N}_{2} \mathrm{O}$ anesthesia for cesarean sections.

Methods: We selected 68 pregnant women with a single fetus undergoing an elective cesarean section under general anesthesia and randomly allocated them to the thiopental sodium group (group $\mathrm{N}$ ) or the propofol group (group P). Without premedication, thiopental sodium $5 \mathrm{mg} / \mathrm{kg}$ and succinylcholine 1 $\mathrm{mg} / \mathrm{kg}$ were injected for induction in group $\mathrm{N}$, and propofol $2 \mathrm{mg} / \mathrm{kg}$ and succinylcholine $1 \mathrm{mg} / \mathrm{kg}$ in group P. Propofol $10 \mathrm{mg} / \mathrm{kg} / \mathrm{hr}$ was infused continuously with $50 \% \mathrm{~N}_{2} \mathrm{O}$ in both groups. We checked the blood pressure and the heart rate before and after injection. We analysed blood gas of maternal artery, umbilical artery, and umbilical vein at delivery and checked Apgar scores at 1 minute and 5 minutes after delivery.

Results: There was no significant difference in blood pressure, heart rate and Apgar scores between groups. Oxygen partial pressure $(35.6 \pm 5.8 \mathrm{mmHg})$ and oxygen saturation $(66.2 \pm 12.0 \%)$ of the umbilical vein in group $\mathrm{P}$ was higher than in group $\mathrm{N}(32.7 \pm 4.9 \mathrm{mmHg}, 58.7 \pm 11.5 \%)$. Carbon dioxide partial pressure and $\mathrm{pH}$ did not differ between groups.

Conclusions: There was no beneficial effect of thiopental sodium compared with propofol as an induction agent under propofol anesthesia. Propofol is a useful drug for cesarean sections. (Korean J Anesthesiol 2001; 40: 335 339)

Key Words: Anesthesia: obstetric. Anesthetics, intravenous: propofol; thiopental sodium.

논문접수일 : 2000년 10월 13 일

책임저자 : 황정원, 서울시 도봉구 쌍문 3 동 한일병원 마취과, 우편번호: 140-757 Tel: 02-901-3158, Fax: 02-901-3153 E-mail: jungwonh@chollian.net
서 론

제왕절개술은 수술시간이 짧고 수술 후 구역 및 구토의 발생 가능성이 크다. Propofol은 정맥마취제 로서 제거반감기가 짧아 회복이 빠르고 ${ }^{1-3)}$ 수술 후 구역 및 구토의 빈도를 줄이므로 금식시간이 충분하 
지 않거나 비만 등 구토의 위험성이 증가된 환자에 게 좋은 마취제이다. ${ }^{4)}$ 실혈과 아기의 분만으로 인한 propofol의 손실 때문에 제왕절개술에서의 propofol 청소율은 다른 수술에서보다 빠르다. ${ }^{2)}$ 그러므로 제 왕절개술시 propofol을 사용한다면 명쾌한 각성과 구 토억제를 기대할 수 있을 것이다.

제왕절개술의 마취에서 또 하나 중요한 것은 신생 아에 미치는 약물의 영향을 최소화하는 것이다. 마 취유도제 또한 태아에게 안전해야 하며 이에 적합한 약물을 찾기 위한 노력이 계속되었다. Thiopental sodium은 태반이동이 빨라서 태아에게 절대적으로 안전 한 약물은 아니지만 ${ }^{5}$ 오래 전부터 관습적으로 제왕절 개술의 마취유도제로 사용되어져 왔다. Propofol 역시 빠른 태반이동으로 인해 분만 전 이미 태아의 혈액 내에서 propofol이 발견되지만 ${ }^{1,6}$ 여러 가지 상기한 장점들로 인해 그 사용범위가 점차 넓어지고 있다. 제왕절개술에서 마취유도제로 사용한 thiopental sodium과 propofol이 태아에 미치는 영향을 비교한 연구 가 여러 가지 있었지만 ${ }^{7-11)}$ 그 결론에 대해서는 아직 논란이 많다. Valtonen 등은 ${ }^{9)}$ 신생아에 대한 영향에 있어서 propofol과 thiopental sodium의 차이가 없다고 하였다. Celleno 등은,12) 연구결과를 제시하며 제왕 절개술시 propofol보다 thiopental sodium을 사용할 것 을 권장하였다. 또한 $\mathrm{Gin}$ 등에 ${ }^{1)}$ 의하면 propofol의 총투여량이 많으면 많을수록 태아에 미치는 영향이 커진다고 하였다. 그렇다면 propofol을 사용하여 제 왕절개술을 마취할 때, 마취유도 및 유지를 모두 propofol로 하는 것보다 thiopental sodium으로 마취를 유도하여 propofol의 총투여량을 줄이는 것이 태아에 대한 영향을 작게 할 수도 있을 것이다.

본 연구에서는 propofol- $\mathrm{N}_{2} \mathrm{O}$ 를 사용하여 제왕절개 술을 마취할 때 마취유도제로서의 thiopental sodium 과 propofol이 임산부의 활력징후와 신생아에 미치는 영향을 알아보고자 하였다. 이를 위해 마취유도약물 주입 전, 후 임산부의 혈압과 심박수를 측정하였으 며 분만 직후 제대동, 정맥의 가스분석을 시행하고 Apgar 점수를 측정한 후 비교 분석하였다.

\section{대상 및 방법}

전신마취 하에 제왕절개술을 받는 임산부 중에서 조기출산이 아니고 수술 전 태아의 상태가 나쁘지
Table 1. Demographic Data

\begin{tabular}{lcc}
\hline \hline & Group N & Group P \\
\hline $\begin{array}{l}\text { Sample size } \\
\text { Age (yr) }\end{array}$ & 34 & 34 \\
$\begin{array}{l}\text { Body weight } \\
(\mathrm{kg})\end{array}$ & $69.8 \pm 3.7$ & $30.2 \pm 3.5$ \\
$\begin{array}{l}\text { Gestational age } \\
\quad(\text { weeks) }\end{array}$ & $38.5 \pm 0.9$ & $69.2 \pm 9.1$ \\
$\begin{array}{l}\text { ITD (sec) } \\
\text { Dosage of } \\
\text { propofol (mg) }\end{array}$ & $330.6 \pm 69.9$ & $330.5 \pm 50.4$ \\
\hline
\end{tabular}

Values are expressed by mean \pm SD. ITD: induction to delivery.

않았던 산모와 그 신생아 68 쌍을 대상으로 하였다. 미국 마취과학회 환자 분류등급 1 또는 2 에 해당하 였으며 분만통이 심한 자는 제외시켰다. 무작위로 두 군으로 나누어 마취유도 약물을 달리 하였다. 각 군별 임산부의 연령, 체중, 제태기간, 분만까지 걸린 시간(induction to delivery, ITD) 및 분만 전 주입된 propofol의 용량의 분포를 Table 1 에 정리하였으며 분포에 있어서 군간의 차이는 보이지 않았다.

마취 전 투약은 하지 않았으며 마취유도 전 수축 기, 평균, 이완기혈압과 심박수를 측정하였다(Dinamap MPS, Johnson and Johnson, USA), 무작위로 두 군으 로 나누어 한 군은(N군) $5 \mathrm{mg} / \mathrm{kg}$ 의 thiopental sodium을, 다른 군은(P군) $2 \mathrm{mg} / \mathrm{kg}$ 의 propofol을 $1 \mathrm{cc} / \mathrm{sec}$ 의 속도로 정주하여 마취를 유도하였으며 ${ }^{12)}$ 두 군 모두 마취유지를 위해 propofol을 $10 \mathrm{mg} / \mathrm{kg} / \mathrm{h}$ 의 속도 로 지속정주하였다. 정주시작 1 분 후에 혈압과 심박 수를 재측정하였으며 succinylcholine $1 \mathrm{mg} / \mathrm{kg}$ 정주 후 기관내 삽관을 시행하였다. 기관내 삽관 후 vecuro$\operatorname{nium} 3 \mathrm{mg}$ 을 정주하였으며 아산화질소와 산소를 $1 \mathrm{~L}$ $: 1 \mathrm{~L}$ 로 투여하였다. 호기말 이산화탄소분압이 30 $\mathrm{mmHg}$ 가 되도록 분시환기량을 조절하였다. 마취유도 약물 주입시작부터 아기가 태어나 탯줄을 결찰할 때 까지의 시간(ITD)을 측정하였으며 아기 탄생 직후 신생아 쪽의 제대동맥, 제대정맥과 산모의 요골동맥 에서 혈액을 체취하여 $\mathrm{pH}$, 이산화탄소분압, 산소분 압, 산소포화도를 측정하고 출생 1 분과 5 분 후에 Apgar 점수를 측정하였다.

모든 관찰치는 평균 \pm 표준편차로 표시하였다. 
Table 2. Maternal Blood Pressure and Heart Rate

\begin{tabular}{|c|c|c|c|c|}
\hline & \multicolumn{2}{|c|}{ Group N } & \multicolumn{2}{|c|}{ Group P } \\
\hline & Pre & Post & Pre & Post \\
\hline SBP (mmHg) & $117.4 \pm 16.3$ & $112.1 \pm 19.1^{*}$ & $117.0 \pm 11.4$ & $109.7 \pm 15.5^{*}$ \\
\hline MBP $(\mathrm{mmHg})$ & $87.9 \pm 10.6$ & $87.6 \pm 13.8$ & $88.9 \pm 9.9$ & $87.0 \pm 14.8$ \\
\hline DBP (mmHg) & $70.4 \pm 10.2$ & $71.4 \pm 11.8$ & $72.6 \pm 12.1$ & $70.4 \pm 13.6$ \\
\hline HR (bpm) & $79.3 \pm 15.4$ & $95.2 \pm 17.9 *$ & $80.7 \pm 12.5$ & $96.9 \pm 16.4^{*}$ \\
\hline
\end{tabular}

Values are expressed by mean \pm SD. SBP: systolic blood pressure, MBP: mean blood pressure, DBP: diastolic blood pressure, HR: heart rate, pre: pre-injection, post: at 1 minute after injection. *: $\mathrm{P}<0.05$ pre vs post.

Table 3. Umbilical Cord Blood Gas Analysis

\begin{tabular}{|c|c|c|}
\hline & Group $\mathrm{N}$ & Group P \\
\hline Arterial pH & $7.333 \pm 0.022$ & $7.328 \pm 0.022$ \\
\hline $\mathrm{PaCO}_{2}(\mathrm{mmHg})$ & $53.0 \pm 4.1$ & $53.3 \pm 4.4$ \\
\hline $\mathrm{PaO}_{2}(\mathrm{mmHg})$ & $21.7 \pm 2.9$ & $22.6 \pm 3.3$ \\
\hline $\mathrm{SaO}_{2}(\%)$ & $32.7 \pm 7.3$ & $35.4 \pm 9.0$ \\
\hline Venous $\mathrm{pH}$ & $7.364 \pm 0.020$ & $7.361 \pm 0.024$ \\
\hline $\mathrm{PvCO}_{2}(\mathrm{mmHg})$ & $45.9 \pm 3.1$ & $45.3 \pm 2.9$ \\
\hline $\mathrm{PvO}_{2}(\mathrm{mmHg})$ & $32.7 \pm 4.9$ & $35.6 \pm 5.8^{*}$ \\
\hline $\mathrm{SvO}_{2}(\%)$ & $58.7 \pm 11.5$ & $66.2 \pm 12.0^{*}$ \\
\hline
\end{tabular}

Values are expressed by mean $\pm \mathrm{SD}$. $\mathrm{PaCO}_{2}$ : partial pressure of dioxycarbon in umbilical artery, $\mathrm{PaO}_{2}$ : partial pressure of oxygen in umbilical artery, $\mathrm{SaO}_{2}$ : saturation of oxygen in umbilical artery, $\mathrm{PvCO}_{2}$ : partial pressure of dioxycarbon in umbilical vein, $\mathrm{PvO}_{2}$ : partial pressure of oxygen in umbilical vein, $\mathrm{SvO}_{2}$ : saturation of oxygen in umbilical vein. *: $\mathrm{P}<0.05$ Group $\mathrm{N}$ vs Group P.

연령, 체중, 제태기간, 혈액가스 분석소견과 Apgar 점수의 군간 비교는 'Rank sum test'를 이용하였다. 약물주입에 따른 혈압과 심박수의 변화유무를 알기 위해 'Paired t-test'를 시행하였으며 그 변화정도에 있어서 두 군간의 차이가 있는지 여부를 알기 위해 'repeated measures ANOVA'를 이용하였다. 제대동, 정맥 산소분압 및 산소포화도와 $\mathrm{ITD}$ 와의 상관관계 를 알아보기 위하여 'Spearman 상관분석'을 시행하 였다. 모든 경우에 있어서 $\mathrm{P}$ 값이 0.05 미만일 때 통 계적으로 유의하다고 판단하였다.

$$
\text { 결 과 }
$$

마취유도약물 주입 전후의 혈압 및 심박수 변화는
Table 4. Maternal Arterial Blood Gas Analysis

\begin{tabular}{lcc}
\hline \hline & Group N & Group P \\
\hline $\mathrm{pH}$ & $7.333 \pm 0.022$ & $7.328 \pm 0.022$ \\
$\mathrm{PaCO}_{2}(\mathrm{mmHg})$ & $53.0 \pm 4.1$ & $53.3 \pm 4.4$ \\
$\mathrm{PaO}_{2}(\mathrm{mmHg})$ & $21.7 \pm 2.9$ & $22.6 \pm 3.3$ \\
$\mathrm{SaO}_{2}(\%)$ & $32.7 \pm 7.3$ & $35.4 \pm 9.0$ \\
\hline
\end{tabular}

Values are expressed by mean $\pm \mathrm{SD} . \mathrm{PaCO}_{2}$ : arterial partial pressure of dioxycarbon, $\mathrm{PaO}_{2}$ : arterial partial pressure of oxygen, $\mathrm{SaO}_{2}$ : arterial saturation of oxygen.

Table 2에 기술하였다. 두 군 모두에서 약물 주입 후 수축기 혈압은 감소하고 심박수는 증가하였으며 $(\mathrm{P}$ $<0.05)$ 그 정도에 있어서 두 군간의 차이는 없었 다(P>0.05). 평균 혈압 및 이완기 혈압은 약물 주 입 후에도 유의한 변화를 보이지 않았다(P>0.05).

신생아에서 출생 후 1 분과 5 분의 Apgar 점수를 살 펴보면 $\mathrm{N}$ 군에서는 $7.5 \pm 1.1$ 과 $9.3 \pm 0.7, \mathrm{P}$ 군은 $7.8 \pm 1.0$ 과 $9.5 \pm 0.7$ 로서 두 군간의 차이는 없었 다 $(\mathrm{P}>0.05)$. 어느 군에서도 심각한 호흡곤란이나 심장박동이상을 보이는 신생아는 없었다.

신생아의 혈액가스소견을 Table 3에 정리하였다. 제대동맥과 정맥의 $\mathrm{pH}$ 및 이산화탄소분압은 두 군 간 차이를 보이지 않았다 $(\mathrm{P}>0.05)$. 제대동맥의 산 소분압과 산소포화도 역시 두 군의 차이가 없었지만 $(\mathrm{P}>0.05)$ 제대정맥 산소분압과 산소포화도는 $\mathrm{P}$ 군 이 각각 $35.6 \pm 5.8 \mathrm{mmHg}$ 와 $66.2 \pm 12.0 \%$ 이고 $\mathrm{N}$ 군이 $32.7 \pm 4.9 \mathrm{mmHg}$ 와 $58.7 \pm 11.5 \%$ 로서 $\mathrm{P}$ 군이 $\mathrm{N}$ 군보다 높았다 $(\mathrm{P}<0.05)$. 분만 직후 산모의 동맥 혈 이산화탄소분압, 산소분압 및 산소포화도는 두 군간 차이를 보이지 않았다 $(\mathrm{P}>0.05$, Table 4$)$. 


\section{고 찰}

본 연구결과를 볼 때 제왕절개술의 마취시 propofol의 총투여량을 줄이기 위해 thiopental sodium으 로 마취유도하는 것이 마취의 유도 및 유지를 모두 propofol로 하는 것보다 산모와 태아에게 더 좋은 점 이 없음을 알 수 있다.

제왕절개술의 마취유도는 되도록 신속하게 시행되 어야 하기 때문에 일반적으로 작용발현시간이 빠른 근이완제를 사용하고 최면유도 후 보통 1 분 이내에 기관내 삽관을 시행한다. 기관내 삽관은 매우 큰 자 극이므로 마취유도시 이를 위한 마취를 충분히 해야 한다. 그런데 신속한 기관내 삽관이 이루어지는 제 왕절개술에서는 최초의 마취유도 약물이 기관내 삽 관 후 발생하는 혈압의 과도한 상승을 억제하는 역 할을 해야 한다. 본 연구 결과에서 thiopental sodium과 propofol의 정주는 모두 수축기 혈압을 떨어뜨리고 심박수를 증가시켰으며 그 정도에 있어서 차이를 보 이지 않았다. 두 군 모두에서 약물 주입 후 심각한 저혈압이나 빈맥을 유발한 경우는 없었다. 양을 대 상으로 실험했던 Alon 등은 ${ }^{13)}$ propofol의 주입 후 발 생하는 심각한 서맥을 경고했으나 본 연구에서는 propofol 주입 후 서맥이 발생한 경우는 한 번도 없 었으며 오히려 대부분 심박수가 증가하였다. 실험대 상과 약물주입량의 차이에서 나온 결과로 해석된다.

신생아의 1 분과 5 분 Apgar 점수는 $\mathrm{N}$ 군이 각각 7.6, 9.4이고 $\mathrm{P}$ 군은 7.8, 9.5로서 군간 차이를 보이지 않았다. 기존 연구를 살펴볼 때 Celleno 등의 연구결 과에서는 ${ }^{9)}$ propofol로 마취 유도한 군의 1 분 Apgar 점수가 thiopental sodium으로 마취 유도한 군보다 낮 았으며 5분 Apgar 점수는 차이가 없었지만 그 외의 대다수의 연구에서 Apgar 점수의 차이가 없었다. $\mathrm{Gin}$ 등의 연구에서는 ${ }^{1)}$ 제왕절개술 중 주입된 propofol의 총량이 많을 때 출생 15 분 후 신생아의 신 경점수(NACS)가 더 낮았지만 Apgar 점수와 그 외 다른 시각의 신경점수는 차이가 없었다. Apgar 점수 는 저산소증 등 신생아의 심각한 장애를 평가하는데 매우 유용하고 편리한 검사이긴 하지만 비교적 정상 인 신생아에서의 신경학적 평가에 대한 변별력이 적 기 때문일 수도 있다. Kanto 등은 ${ }^{3)}$ 제대정맥의 propofol 농도와 혈액가스 또는 Apgar 점수와의 상관관
계는 없다고 하였다. 본 연구에서도 ITD와 Apgar 점 수의 상관관계는 없었으며 ITD와 혈액가스소견과의 상관성도 없었다. ITD가 237초에서 510초까지 비교 적 짧은 시간이었고 편차가 크지 않기 때문으로 해 석되는데 ITD가 현저하게 크다면 propofol의 총주입 량이 증가하게 되고 그에 따라 제대혈액의 가스소견 의 변화가 나타날 가능성도 배제할 수 없다.

본 연구 결과에서 분만시 산모의 가스분석소견은 두 군의 차이가 없었다. 제대정, 동맥의 $\mathrm{pH}$ 와 이산 화탄소분압도 차이를 보이지 않았지만 제대정맥의 산소포화도와 산소분압만 $\mathrm{P}$ 군이 $\mathrm{N}$ 군보다 더 높았다. 제왕절개술에서 propofol과 thiopental을 비교한 기존 연구들을 볼 때 $7,10,13,14)$ 제대혈액 가스분석의 차이를 보인 연구는 없었다. 본 연구에서 제대동, 정맥의 산 소분압은 $\mathrm{N}$ 군이 $21.7 \mathrm{mmHg}$ 와 $32.7 \mathrm{mmHg}$ 이고 $\mathrm{P}$ 군 은 $22.6 \mathrm{mmHg}, 35.6 \mathrm{mmHg}$ 로서 $15.2 \mathrm{mmHg} 25.8$ $\mathrm{mmHg}$ 를 보인 Richardson의 연구결과보다 ${ }^{14)}$ 좀 높은 편이다. 산소포화도도 $\mathrm{N}$ 군은 $32.7 \%$ 와 $58.7 \%$ 이고 $\mathrm{P}$ 군은 $35.4 \%, 66.2 \%$ 로서 기존 연구보다 높지만 $\mathrm{pH}$ 와 이산화탄소분압은 비슷하다. ${ }^{10,14-16,18)}$

수술 중 자극으로 인해 catecholamine의 분비가 많 아지면 혈관저항이 증가하여 자궁으로 가는 혈류량 이 감소한다. ${ }^{17)}$ Alon 등은 ${ }^{13)}$ thiopental sodium으로 마 취를 유도한 경우에서 일시적으로 자궁혈류량이 감 소하였다가 isoflurane의 사용 후 다시 증가하였지만 propofol을 사용했을 때는 자궁혈류량이 유지되거나 약간 증가하였다고 보고하였다. 본 연구에서 $\mathrm{N}$ 군의 제대정맥혈 산소포화도 및 산소분압이 $\mathrm{P}$ 군보다 낮았 던 원인을 자궁 혈류량 저하로 볼 수 있다. 본 연구 에서 ITD는 N군이 $330.6 \pm 69.9$ 초이고 $\mathrm{P}$ 군은 330.5 \pm 50.4초로서 기존 연구결과보다 ${ }^{1,7)}$ 매우 짧은데 thiopental sodium의 주입 후 감소한 자궁혈류량이 원상 태로 회복하기 전에 분만이 이루어졌을 가능성도 배 제할 수 없다. 제대정맥혈이 태반의 상태를 반영하 는 반면에 제대동맥혈은 태아의 상태를 반영한다고 할 수 있다. ${ }^{18-20)}$ 태아의 혈액가스분석 중에서 중요한 것은 $\mathrm{pH}$ 이다. 태아의 산소해리곡선의 특성상 산소분 압은 의외로 그 중요성이 적으멸) 산소포화도도 $\mathrm{pH}$ 나 임상양상과의 상관성이 적다. ${ }^{14,21)}$ 본 연구결과에서 도 $\mathrm{P}$ 군의 제대정맥 산소분압이 $\mathrm{N}$ 군보다 컸지만 그것 의 임상적 의미는 크지 않다고 생각된다.

이상으로 볼 때 제왕절개술의 마취시 마취의 유도 
와 유지를 모두 propofol로 하는 것이 propofol의 총 투여량을 줄이고자 마취유도는 thiopental sodium으로 하는 것보다 산모와 태아에게 더 불리하지 않으며 propofol이 제왕절개술에서 thiopental sodium을 대체 할 수 있는 유용한 마취약제라고 할 수 있다.

\section{참 고 문 헌}

1. Gin T, Yau G, Chan K, Gregory MA, Oh TE: Disposition of propofol infusions for Caesarean section. Can J Anaesth 1991; 38: 31-6.

2. Gin T, Gregory MA, Chan K, Buckley T, Oh TE: Pharmacokinetics of propofol in women undergoing elective Caesarean section. Br J Anaesth 1990; 64: 148-53.

3. Kanto J, Rosenberg P: Propofol in Caesarean section. A pharmacokinetic and pharmacodynamic study. Methods Find Exp Clin Pharmacol 1990; 12: 707-11.

4. Gan TJ, Glass PS, Howell ST, Canada AT, Grant AP, Ginsberg B: Determination of plasma concentrations of propofol associated with $50 \%$ reduction in postoperative nausea. Anesthesiology 1997; 87: 779-84.

5. Esener Z, Sarihasan B, Guven H, Ustun E: Thiopentone and etomidate concentrations in maternal and umbilical plasma, and in colostrum. $\mathrm{Br} \mathrm{J}$ Anaesth 1992; 69: 586-8.

6. Sanchez-Alcaraz A, Quintana MB, Laguiarda M: Placental transfer and neonatal effects of propofol in Caesarean section. J Clin Pharm Ther 1998; 23: 1923.

7. Yau G, Gin T, Ewart MC, Kotur CF, Leung RKW, Oh TE: Propofol for induction and maintenance of anaesthesia at Caesarean section. Anaesthesia 1991; 46: $20-3$.

8. Celleno D, Capogna G, Tomassetti M, Costantino P, Feo GD, Nisini R: Neurobehavioural effects of propofol on the neonate following elective Caesarean section. Br J Anaesth 1989; 62: 649-54.

9. Valtonen M, Kanto J, Rosenberg P: Comparison of propofol and thiopentone for induction of anaesthesia for elective Caesarean section. Anaesthesia 1989; 44: 758-62.

10. Siafaka I, Vadalouca A, Gatziou B, Petropoulos G,
Salamalekis E: A comparative study of propofol and thiopental as induction agents for elective Caesarean section. Clin Exp Obstet Gynecol 1992; 19: 93-6.

11. 소상윤, 박장훈, 박현경, 송희선, 최 훈, 한영진: 제왕절 개술을 위한 thiopental sodium-enflurane- $\mathrm{N}_{2} \mathrm{O}$ 마취와 propofol- $\mathrm{N}_{2} \mathrm{O}$ 마취가 산모와 신생아에 미치는 영향. 대 한마취과학회지 1996; 30: 470-8.

12. 황정원, 오용석, 한성희: Midazolam을 전투약한 환자에 서 Propofol 용량에 따른 의식 소실과 무호흡의 빈도. 대한마취과학회지 1997; 33: 68-72.

13. Alon E, Ball RH, Gillie MH, Parer JT, Rosen MA, Shnider SM: Effects of propofol and thiopental on maternal and fetal cardiovascular and acid-base variables in the pregnant ewe. Anesthesiology 1993; 78: 562-76.

14. Richardson B, Nodwell A, Webster K, Alshimmiri M, Gagnon R, Natale R: Fetal oxygen saturation and fractional extraction at birth and the relationship to measures of acidosis. Am J Obstet Gynecol 1998; 178: $572-9$.

15. Dickinson JE, Eriksen NL, Meyer BA, Parisi VM: The effect of preterm birth on umbilical cord blood gases. Obstet Gynecol 1992; 79: 575-8.

16. Khoury AD, Moretti ML, Barton JR, Shaver DC, Sibai BM: Fetal blood sampling in patients undergoing elective cesarean section: A correlation with cord blood gas values obtained at delivery. Am J Obstet Bynecol 1991; 165: 1026-9.

17. Gin T, O'meara ME, Kan AF, Leung RKW, Tan P, Yau G: Plasma catecholamines and neonatal condition after induction of anaesthesia with propofol or thiopentone at Caesarean section. Br J Anaesth 1993; 70: 311-6.

18. Thorp JA, Dildy GA, Yeomans ER, Meyer BA, Parisi VM: Umbilical cord blood gas analysis at delivery. Am J Obstet Gynecol 1996; 175: 517-22.

19. Westgate J, Garibaldi JM, Greene KR: Umbilical cord blood gas analysis at delivery: a time for quality data. Br J Obstet Gynaecol 1994; 101: 1054-63.

20. Thorp JA, Rushing RS: Umbilical cord blood analysis. Obstet Gynecol Clic North Am 1999; 26: 695-709.

21. Arikan GM, Scholz HS, Haeusler MC, Giuliani A, Haas J, Weiss PA: Low fetal oxygen saturation at birth and acidosis. Obstet Gyneco 2000; 95: 565-71. 